Journal of Thermal Engineering, Vol. 7, No.1, pp. 91-108, January, 2021

Yildiz Technical University Press, Istanbul, Turkey

\title{
FINITE ELEMENT SOLUTION OF HYDROMAGNETIC MIXED CONVECTION IN A NANOFLUID FILLED VENTED GROOVED CHANNEL
}

\author{
Mohammad Mokaddes Ali1, ${ }^{*}$, Md. Abdul Alim², Syed Sabbir Ahmed ${ }^{3}$
}

\begin{abstract}
The mixed convection flow in a differentially heated grooved channel filled with water based nanofluid under the influence of external magnetic field has been analyzed numerically in this study. Nanofluid's thermal conductivity model has been modified to develop a new physical problem and finite element method has been implemented to solve the dimensionless governing equations. Numerical simulations have been performed for different values of pertinent parameters. Fluid flow and temperature distributions have been exhibited in terms of streamlines and isotherms due to the variation of Richardson number, Hartmann number and concentration of nanoparticles in base fluid water. The results show that flow field and temperature distributions within the channel affected significantly with the effects of Richardson number, Hartmann number and concentration of nanoparticles. In addition, it is found that heat transfer rate increases and decreases respectively with the increase in strength of magnetic field which depends strongly on Richardson number. Moreover, heat transfer rate accelerates effectively for increasing volume fraction, Reynolds number and Richardson number. The present simulation has been validated by comparing the present results with other published works on the basis of special cases.
\end{abstract}

\section{Keywords: Magnetic Field, Mixed Convection, Grooved Channel, Finite Element Method}

\section{INTRODUCTION}

The mixed convection heat transfer in presence of external magnetic effects in closed or open enclosures were studied by many researchers because of its industrial and engineering applications including heat exchangers, cooling of electronic devices, heating and cooling system in building, solar collectors, nuclear reactors, chemical processing equipments, liquid metals, crystal growth, geothermal reservoirs, thermal insulations, drying technologies and other industrial processes etc. The efficiency of such thermal systems is closely related to the heat transfer mechanisms. Different techniques are used to improve the efficiency of heat transfer mechanisms. The utilization of nanofluids instead of traditional heat transfer fluids is a promising way to improve the heat transfer efficiency and also the geometrical modification of thermal managements. Thus, the applications of nanofluids and new designing of a process play vital role in engineering applications. Considering these importance, a number of numerical and experimental studies have been reported by several investigators.

Najam et al. [1] analyzed numerically unsteady mixed convection in a two dimensional channel with heating blocks positioned on the lower wall. Their results showed that natural convection cells are moving downstream for the obtained periodic velocities due to critical Reynolds numbers studied. They also noted that natural convection cells disappeared and heat transfer rate decreased with the higher values of Reynolds number. Aminossadati and Ghasemi [2] conducted a similar investigation by considering discrete heat sources at different locations of the channel and they reported that the heat transfer improvement strongly depends on the cavity aspect ratio and position of the heat source for certain value of Richardson number. Later on, they [3] considered nanofluid filled lid-driven triangular enclosure to analyze the heat transfer augmentation due to mixed convection flow and found that the addition of nanoparticles increase the heat transfer rate for all Richardson number at any direction of the sliding walls. Shahi et al. [4] used finite volume approach to obtain numerical solution of mixed convection in a square ventilated cavity and found that average Nusselt number increases and bulk temperature decreases for increasing solid concentration. Fereidoon et al.

This paper was recommended for publication in revised form by Regional Editor Baha Zafer

${ }^{1}$ Department of Mathematics, Mawlana Bhashani Science and Technology University, Tangail-1902, Bangladesh

2 Department of Mathematics, Bangladesh University of Engineering and Technology, Dhaka-1000, Bangladesh

${ }^{3}$ Department of Mathematics, Jahangirnagar University, Saver, Dhaka-1342, Bangladesh

*E-mail address: mmali309@gmail.com, maalim@math.buet.ac.bd, fahim@juniv.edu

Orcid Id:0000-0001-7508-6927, 0000-0001-9706-2221

Manuscript Received 08 November 2018, Accepted 22 January 2019 
[5] performed a similar study by considering inclined square double lid driven cavity. They demonstrated that heat transfer rate increased significantly with greater values of governing parameters than lower ones. Hussein and Hussain [6] presented a numerical study of mixed convection in a two sided lid driven parallelogramic cavity under the effect of magnetic field. They found that heat transfer rate and fluid flow affected with increase in Richardson number and the direction of lid-walls of the parallelogramic cavity. They also confirmed the circulation of the rotating vortices was reduced with increase in magnetic field effect. The problem of heat transfer enhancement for corrugated channel was numerically studied by Tokgoz et al. [7] and they recommended the rate of turbulent intensity along the central axis of the channel and the thermal performance in this duct were increased due to the corrugated surfaces.

Later on, Ogut [8] introduced second law of thermodynamics to analyze mixed convection in an inclined liddriven cavity in presence of magnetic field and pointed out the fluid flow and entropy generation decrease for increase in Hartmann number. After that, the heatline visualization technique was first time implemented by Zahmatkesh and Ardekani [9] to investigate the effect of magnetic field orientation on free convection flow of nanofluids in a square porous cavity. Their results demonstrated the heat transfer rate deteriorates for the increase in magnetic field strength. Finite difference method based numerical study [10] of MHD mixed convection in a lid driven cavity with Joule heating effect indicated the heat transfer rate increased by the increasing Richardson number and volume fraction, and decreased by increasing of Hartmann number and Eckert number. Nasrin et al. [11] used Galerkin's finite element method to simulate mixed convection in copper oxide-water nanofluid filled triangular wavy enclosure and reported that heat transfer rate is an increasing function of Reynolds number and volume fraction and decreasing function of Richardson number.

Farsani et al. [12] investigated the heat transfer performance and the removal process for magnetohydrodynamic mixed convection in an open cavity. They found that heat transfer rate was accentuated due to increase in Grashof number and decelerated with increase in Reynolds and Hartmann numbers while opposite phenomena reflected in the removal process of fluid particles. Abu-Mulaweh [13] presented a comprehensive review of the flow and heat transfer results for laminar mixed convection flow over vertical, horizontal and inclined backwardfacing and forward-facing steps and summarized that laminar mixed convection flow over a forward-facing step received very little attention comparing to that of the backward-facing step case because of in the forward-facing step geometry, two recirculation regions developed which make it more complicated than the backward-facing step geometry.

Manca et al. [14] numerically studied mixed convection in a channel with an open cavity and their results showed that maximum temperature values decrease with the increase in Reynolds and Richardson numbers and the highest thermal performance in terms of both maximum temperature and average Nusselt number achieved in the opposing forced flow mode. Later on, Manca et al. [15] experimentally investigated this analysis [9] and found that Nusselt numbers increase when the ratio of the length to the height of cavity increase for a considered range of Richardson numbers. Rahman et al. [16] numerically studied the development of magnetic field effect on mixed convective flow in a horizontal channel. Their results indicated that considered governing parameters strongly affect the flow phenomenon and temperature field inside the channel.

Later on, Rahman et al. [17] analyzed the heat transfer, temperature distribution and flow field in a channel heated from different sides and found that the highest heat transfer is obtained when the isothermal heater is located at the right vertical wall. Hossain and Floryan [18] investigated the basic characteristics of fluid movement and heat transfer process associated to the mixed convection in a horizontal channel where the flow was driven by a pressure gradient and the channel was periodically heated and highlighted that largest heat transfer across the channel occurs for the natural convection $(\operatorname{Re}=0)$ and diminishes with an increase of the forced flow component (increase of $\mathrm{Re}$ ). A numerical investigation was performed by Rafi et al. [19] to analyze the flow and thermal fields for steady two dimensional laminar mixed convection flow in a rectangular channel and better cooling performance observed for increasing the Reynolds number in pure mixed convection case.

Rashidi et al. [20] conducted a numerical investigation of mixed convection heat transfer of nanofluid flow in vertical channel with sinusoidal walls under magnetic field effect and they reported that average Nusslet number increases by increase in Grashof number for nanofluids with different volume fractions. It was also noted that the average Nusselt number and Poiseuille number increases by increasing the Hartman number. Carozza [21] performed 
a numerical investigation on mixed convection in a two dimensional open ended cavity with different aspect ratios and focused that the enhancement of heat transfer rate depends on the increasing Re and the assisting configuration. Devera and Hyhlik [22] conducted an experimental study to investigate the thermal field in a horizontal rectangular channel with two types of bottom boundary conditions and concluded that mass transfer causes stronger transient behavior above the bottom surface and enhancing of heat transfer, but the overall character of the thermal field remains the same as in case of heat transfer only.

Hussein et al. [23] analyzed the thermal and flow fields characteristics of laminar steady mixed convection flow in a rectangular inclined lid-driven cavity filled with water-based nanofluids. They found that the local Nusselt number decreases with the increased inclination angle and solid volume fraction and the shape of the circulation vortex was sensitive to the inclination angle and addition of nanofluids. Mohammed et al. [24] reported numerical simulations for buoyancy-opposing laminar mixed convection using various types of nanofluids with $5 \%$ volume fraction over a backward-facing step in a vertical duct. Their results revealed that recirculation region developed behind the backwardfacing step in the case of forced convection and low buoyancy opposing level disappeared when the buoyancyopposing increased. They also noted that skin friction coefficient decreases as Reynolds number and Prandtl number increases.

Ahmed et al. [25] utilized finite volume method to investigate numerically the thermal and flow fields characteristics for laminar steady mixed convection flow in a square lid-driven enclosure filled with water-based micropolar nanofluids and found that enhancement of average Nusselt number depends on the length of heat source and solid volume fraction. Al-Rashed et al. [26] performed three dimensional numerical simulations on mixed convection in a cubical enclosure filled with nanofluid using vorticity-vector potential formalism. Their results indicated that thermal entropy generation increases by increasing the concentration of nanoparticles for all Richardson numbers, but the variation viscous entropy generation with concentrations depends on Ri values.

Chau and Jiang [27] developed and implemented a three-dimensional numerical model based on an orthogonal curvilinear grid system in the horizontal direction and a sigma coordinate system in the vertical direction for the prediction of water quality constituents. Their results illustrated that the pollutants from the Pearl River Delta Region (PRDR) have certain impact on the Hong Kong seawaters, especially during the wet season when the discharge rates are high at the upstream ends. Afterward, they [28] developed a three-dimensional numerical pollutant transport model coupling with previously developed hydrodynamic models and observed a transboundary action between Guangdong province and Hong Kong special administrative region for the pollutants in the wastewater discharged from the Pearl River Delta Region.

Wu and Chau [29] presented a mathematical model of water quality rehabilitation by utilizing rainwater to reduce significantly both the project investment and operation costs and also suggested appropriate drainage plan scheme to address the initial polluted rainwater problem. Ardabili et al. [30] reviewed the survey of the state-of-theart computational intelligenc (CI) approaches used in hydrogen production in terms of their context of application, accuracy and sensitivity to the model's input datasets and provides in-depth insight into the different hydrogen production methods and modeling technique and focused their future viewpoint to develop a multifactor system-based CI applied to hydrogen production methods to reach the high performance in estimating and modeling on hydrogen production data.

Akbarian et al. [31] performed a numerical simulation of using natural gas in a dual-fueled constant-speed diesel engine and obtained results indicated that under different loads and pilot to gaseous fuel (PGF) ratios, the emissions of nitrous oxides and particle materials in the dual mode were lower than diesel engine. Ma et al. [32] developed a mathematical model describing gas-liquid valves' motion and dynamical simulation of combined valves to analyze its working mechanism in reciprocating multiphase pump and provide theoretical foundation for the design of new type of multiphase pump. Das et al. [33] developed a model to study mixed convection problem under the influence of uniform transverse magnetic force and observed that nanofluid velocity inside the channel enhanced by the imposed magnetic force. It was also pointed out that the instability of the flow field moderated with considered particle concentrations and magnetic field for critical values of Rayleigh number.

Bansal and Chatterjee [34] studied numerically two-dimensional magneto- mixed convective flow in a liddriven square enclosure with centrally placed circular cylinder. They observed that drag coefficient increases for 
magnetic strength as well as nanoparticle concentration and decreases with mixed convective strength, and the heat transfer enhancement affected by mixed convective strength as well as nanoparticle concentration. Gul et al. [35] studied heat transfer in magnetohydrodynamic (MHD) mixed convection flow of ferrofluid along a vertical channel and found that the temperature and velocity distributions of ferrofluids depend strongly on viscosity and thermal conductivity together with magnetic field. Magnetohydrodynamic mixed convection of hybrid nanofluid flow in a horizontal channel was numerically studied by Hussain et al. [36]. Their results highlighted that the mixed convection mode and rate of heat transfer increased with increasing Richardson number and decreased for magnetic effect. They also noted that the heat transfer rate augmented with increase in Reynolds number and nanoparticle volume fraction.

In addition, the efficiency of thermal managements can be improved by using modified configuration with additional surface area like baffle, fin, corrugate, groove etc. In this context, many researchers have been interested to work on the heat transfer enhancement by using different grooved enclosures. McGarry et al. [37] numerically investigated the flow structures and heat transfer enhancement for grooved channel flow in presence of curved vanes and explained that the best location of vanes increased the cooling rate and decreased pressure drop and vortices were generated due to the presence of curved vanes which were increased in size as the Reynolds number increased. Selvaraj et al. [38] experimentally analyzed the convective heat transfer coefficient in water and ethylene glycol mixture fluid through a grooved tube of different shaped. They reported that Nusselt number and thermal hydraulic performance were higher for the square grooved tube than the other studied and also grater Reynolds number.

Heshmati et al. [39] utilized the finite volume method along with second order upwind technique to study the unsteady laminar forced convection flow over periodic grooved channel and concluded that $4 \%$ concentration of nanoparticles provides the highest heat transfer augmentation and skin friction coefficient. Sharma et al. [40] analyzed the flow and heat transfer complexities for mixed convection in a grooved channel in the presence of an adiabatic baffle which was placed at the top wall. They demonstrated that heat transfer varied upon the baffle height and fluid flow characteristics. Rabbi et al. [41] studied numerically magnetohydrodynamic mixed convection Poiseuille flow through a horizontal channel in presence of a rectangular obstacle using non-Newtonian power law fluid. They observed that heat transfer was optimum in Pseudo-plastic fluid $(n<1)$ than Newtonian fluid and dilatant fluid. It was also pointed out that heat transfer was maximum at higher Hartmann number and Rayleigh number for pseudo-plastic non-Newtonian fluid flow.

Ali et al. [42] numerically analyzed the effect of magnetic field on natural convection flow and heat transfer properties in a grooved enclosure filled with nanofluid. Their results indicated that the heat transfer rate increases with the increase in Rayleigh number and solid volume fraction of nanoparticales but decreases for increasing strength of magnetic field. Later on, they [43] performed a numerical study of magnetic field orientation on mixed convection flow in a grooved channel and highlighted that heat transfer rate affected significantly with the strength and inclination angle of applied magnetic field.

Based on the above literature review, it is evident that no attention has been dedicated to investigate the effect of mixed convection flow in a nanofluid filled grooved channel with ventilation ports. But it was established by many researchers that nanofluids are more effective in terms of heat transfer performance. Accordingly, the utilization of nanofluids within a new geometry like vented grooved channel with appropriate mathematical modification may have significant applications in thermal engineering fields. The purpose of this investigation is to numerically analyze the fluid flow and temperature distribution for mixed convective flow in a differentially heated vented grooved channel filled with nanofluid under the influence of magnetic field. The effects of pertinent parameters including Richardson number, Hartmann number and volume fraction of nanoparticales on the flow structure and temperature distribution have been investigated and discussed in the following sections. The findings from this study can be a useful guide to design relevant equipments like heat exchangers, cooling of electronic components, heating and cooling system in building, solar collectors, lubrication technologies, drying technologies and others thermal process. Although the geometry here is fixed to a grooved channel, the substantial outcomes can be extended for other complicated geometries.

\section{PHYSICAL MODEL}

A two dimensional rectangular vented channel with square grooves of side length $0.2 \mathrm{H}$ is considered whose length is $\mathrm{L}$ and height is $\mathrm{H}$. The bottom walls are kept at constant temperature $\mathrm{T}_{\mathrm{h}}$ and grooved walls are at temperature 
$\mathrm{T}_{\mathrm{c}}$ while other walls are considered as thermally insulated. The initial temperature of the working fluid is maintained at $T_{c}$ and fluid enters through the inlet port of the channel with velocity $u_{i}$ and temperature $T_{c}$ and then leaves through the outlet port by maintaining convective boundary conditions. The working fluid within the channel is water-based nanofluid containing uniform spherical copper-oxide nanoparticles. The thermophysical properties of base fluid water and copper-oxide nanoparticles are given in Table 1. The boundaries of the channel are maintained no-slip conditions. The physical model of the present problem is illustrated in Figure 1.

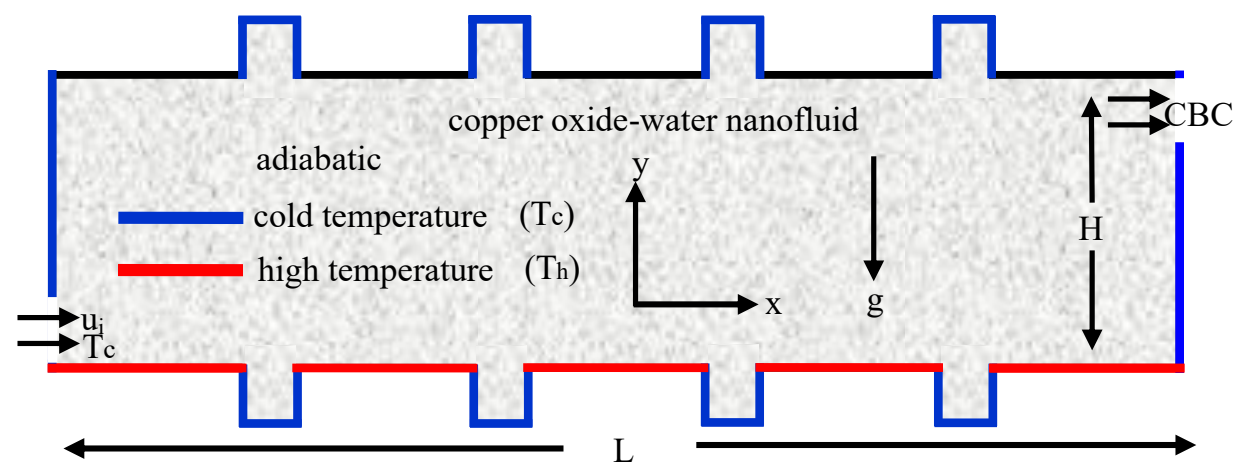

Figure 1. Physical model of the vented grooved channel

Table 1. Thermo physical properties of base fluid and copper-oxide [44]

\begin{tabular}{|c|c|c|}
\hline Physical properties & Base fluid & Copper-oxide (CuO) \\
\hline$C_{p}(\mathrm{~J} / \mathrm{kg} K)$ & 4179 & 540 \\
\hline$\rho\left(\mathrm{kg} / \mathrm{m}^{3}\right)$ & 997.1 & 6500 \\
\hline$k(W / m K)$ & 0.613 & 18 \\
\hline$\beta(1 / K)$ & $2.1 \times 10^{-4}$ & $0.085 \times 10^{-4}$ \\
\hline$\sigma(W / m K)$ & 0.05 & $10^{-10}$ \\
\hline
\end{tabular}

\section{MATHEMATICAL ANALYSIS}

Considering Boussinesq approximation along with aforesaid assumptions, the governing equations for the physical problem can be written as follows $[3,4,11,12,14,16,17,32]$ :

$$
\begin{gathered}
\frac{\partial u}{\partial x}+\frac{\partial v}{\partial y}=0 \\
u \frac{\partial u}{\partial x}+v \frac{\partial u}{\partial y}=-\frac{1}{\rho_{n f}} \frac{\partial p}{\partial x}+\frac{\mu_{n f}}{\rho_{n f}}\left(\frac{\partial^{2} u}{\partial x^{2}}+\frac{\partial^{2} u}{\partial y^{2}}\right) \\
u \frac{\partial v}{\partial x}+v \frac{\partial v}{\partial y}=-\frac{1}{\rho_{n f}} \frac{\partial p}{\partial y}+\frac{\mu_{n f}}{\rho_{n f}}\left(\frac{\partial^{2} v}{\partial x^{2}}+\frac{\partial^{2} v}{\partial y^{2}}\right)+\frac{1}{\rho_{n f}}\left[g \beta_{n f} \rho_{n f}\left(T-T_{c}\right)\right]-\frac{\sigma_{n f}}{\rho_{n f}} B_{0}^{2} v \\
u \frac{\partial T}{\partial x}+v \frac{\partial T}{\partial y}=\frac{k_{n f}}{\left(\rho C_{p}\right)_{n f}}\left(\frac{\partial^{2} T}{\partial x^{2}}+\frac{\partial^{2} T}{\partial y^{2}}\right)+\frac{\sigma_{n f} B_{0}^{2}}{\left(\rho C_{p}\right)_{n f}} v^{2}
\end{gathered}
$$


Journal of Thermal Engineering, Research Article, Vol.7, No.1, pp. 91 - 108, January, 2021

The introduced relations of density, heat capacitance, thermal expansion coefficient, electrical conductivity, thermal conductivity and dynamic viscosity of the nanofluid are given below [11, 33, 36, 45, 46]:

$$
\begin{gathered}
\rho_{n f}=(1-\phi) \rho_{f}+\phi \rho_{s} \\
\left(\rho C_{p}\right)_{n f}=(1-\phi)\left(\rho C_{p}\right)_{f}+\phi\left(\rho C_{p}\right)_{s} \\
\beta_{n f}=(1-\phi) \beta_{f}+\phi \beta_{s} \\
\sigma_{n f}=\sigma_{f}\left(1+\left(\left(3\left(\left(\sigma_{s} / \sigma_{f}\right)-1\right) \phi\right) /\left(\left(\left(\sigma_{s} / \sigma_{f}\right)+2\right)-\left(\left(\sigma_{s} / \sigma_{f}\right)-1\right) \phi\right)\right)\right. \\
\mu_{n f}=\mu_{f}\left(1+39.11 \phi+533.9 \phi^{2}\right) \\
k_{n f}=k_{f}\left(\left(k_{s}+2 k_{f}-2 \phi\left(k_{f}-k_{s}\right)\right) /\left(k_{s}+2 k_{f}+\phi\left(k_{f}-k_{s}\right)\right)\right)
\end{gathered}
$$

The thermal conductivity model of nanofluids proposed by Maxwell's [46] has been extended by incorporating Brownian motion model proposed by Cui et al. [47] to improve the thermal conductivity of nanofluids and the modified model of effective thermal conductivity of nanofluids is given below:

$$
k_{n f}=\frac{\left(k_{s}+2 k_{f}-2 \phi\left(k_{f}-k_{s}\right)\right.}{\left(k_{s}+2 k_{f}+\phi\left(k_{f}-k_{s}\right)\right.} k_{f}+\frac{\phi \rho_{s} c_{s, s}}{2} \sqrt{\frac{2 K_{B} T}{3 \pi d_{s} \mu_{f}}}
$$

The appropriate boundary conditions based on the physical model can be written as:

on the grooved walls : $u=0, v=0, T=T_{c}$

on the inlet: $u_{i}=16 \mathrm{y}(0.5-\mathrm{y}), v=0, T=T_{c}$

on the outlet : $p=0$ and $\frac{\partial u}{\partial x}=\frac{\partial v}{\partial x}=\frac{\partial T}{\partial x}=0$

On the top horizontal walls: $u=v=0, \frac{\partial T}{\partial y}=0$

on the bottom horizontal walls: $u=0, v=0, T=T_{h}$

The following dimensionless quantities are introduced into the governing equations ((1) to (4)) to obtained dimensionless governing equations.

$$
X=\frac{x}{L}, Y=\frac{y}{L}, U=\frac{u}{u_{i}}, V=\frac{v}{u_{i}}, P=\frac{p}{\rho_{n f} u_{i}^{2}} \text {, and } \theta=\frac{T-T_{c}}{T_{h}-T_{c}}
$$


Journal of Thermal Engineering, Research Article, Vol.7, No.1, pp. 91 - 108, January, 2021

Therefore, the dimensionless governing equations are:

$$
\begin{gathered}
\frac{\partial U}{\partial X}+\frac{\partial V}{\partial Y}=0 \\
U \frac{\partial U}{\partial X}+V \frac{\partial U}{\partial Y}=-\frac{\partial P}{\partial X}+\frac{v_{n f}}{v_{f}} \frac{1}{\operatorname{Re}\left(\frac{\partial^{2} U}{\partial X^{2}}+\frac{\partial^{2} U}{\partial Y^{2}}\right)} \\
U \frac{\partial V}{\partial X}+V \frac{\partial V}{\partial Y}=-\frac{\partial P}{\partial Y}+\frac{v_{n f}}{v_{f}} \frac{1}{\operatorname{Re}}\left(\frac{\partial^{2} V}{\partial X^{2}}+\frac{\partial^{2} V}{\partial Y^{2}}\right)+\frac{\beta_{n f}}{\beta_{f}} \operatorname{Ri\theta }-\frac{\rho_{f}}{\rho_{n f}}\left(\frac{\sigma_{n f}}{\sigma_{f}}\right) \frac{H a^{2}}{\operatorname{Re} V} \\
U \frac{\partial \theta}{\partial X}+V \frac{\partial \theta}{\partial Y}=\frac{\alpha_{n f}}{\alpha_{f}} \frac{1}{\operatorname{Re} \operatorname{Pr}}\left(\frac{\partial^{2} \theta}{\partial X^{2}}+\frac{\partial^{2} \theta}{\partial Y^{2}}\right)+\left(\frac{\sigma_{n f}}{\sigma_{f}}\right) \frac{\left(\rho c_{p}\right)_{f}}{\left(\rho c_{p}\right)_{n f}} \frac{H a^{2} E c}{\operatorname{Re}} V^{2}
\end{gathered}
$$

According to the dimensionless scales (10), the associated boundary conditions are converted into following non-dimensional form:

on the grooved walls: $U=0, V=0, \theta=0$.

on the inlet: $U=16 \mathrm{Y}(0.5-\mathrm{Y}), \quad \theta=0$

on the outlet : $P=0$ and $\frac{\partial U}{\partial X}=\frac{\partial V}{\partial X}=\frac{\partial \theta}{\partial X}=0$

on the top horizontal walls: $U=0, V=0, \frac{\partial \theta}{\partial Y}=0$

on the bottom horizontal walls: $U=0, V=0, \theta=1$

Here $\operatorname{Pr}=\frac{v_{f}}{\alpha_{f}}$ is the Prandtl number, $H a^{2}=\frac{\sigma_{f} B_{0}^{2} L^{2}}{\rho_{f} v_{f}}$ is the Hartmann number, $G r=\frac{g \beta_{f}\left(T_{h}-T_{c}\right) L^{3}}{v_{f}^{2}}$ is the Grashof number, $R i=\frac{G r}{\operatorname{Re}^{2}}$ is the Richardson number and $E c=\frac{U_{0}^{2}}{\left(C_{p}\right)_{f}\left(T_{h}-T_{c}\right)}$ is the Eckert number.

\section{EVALUATION OF AVERAGE NUSSELT NUMBER AND AVERAGE TEMPERATURE: Average Nusselt Number}

The heat transfer rate is characterized by local Nusselt number and average Nusselt number respectively, is an important factor of this study. The local Nusselt number $(\bar{N} u)$ is calculated for each heated sections whereas the average Nusselt number $(\mathrm{Nu})$ is calculated for whole domain on the heated walls of the channel by using the following relations $[36,42]$ : 
Journal of Thermal Engineering, Research Article, Vol.7, No.1, pp. 91 - 108, January, 2021

$$
\bar{N} u=-\frac{k_{n f}}{k_{f}} \frac{\partial \theta}{\partial Y} \text { and } N u=\frac{1}{L-0.8 H} \sum_{i=0}^{4} \int_{x_{2 i}}^{x_{2 i+1}} \bar{N} u d X
$$

\section{Average Temperature}

The average temperature of the fluid flow domain within the channel is determined by applying the following equation:

$$
\theta_{a v}=\int(\theta / \bar{V}) d \bar{V}
$$

Here $\bar{V}$ is used to indicate the volume of the enclosure.

\section{GRID SENSITIVITY TEST}

The grid independent test has been performed by considering different mesh systems for average Nusselt number at $\operatorname{Pr}=6.2, \mathrm{Ri}=1, \operatorname{Re}=10, \mathrm{Ha}=20, \phi=1 \%$ and $\mathrm{Ec}=10^{-4}$ and presented in Table 2 as well as in Figure 2, respectively. The computed average Nusselt number for the grid size of 41178 nodes 79640 elements indicates a little difference as compared to the result for other grid sizes. Accordingly, further refinements of grid test have no considerable effects on the computed results of average Nusselt number. Thus, the grid size of 41178 nodes and 79640 elements is filled up the requirement of the grid convergence test and all the computations have been carried out at this meshing.

Table 2. Grid sensitivity test at $\operatorname{Pr}=6.2, \mathrm{Ri}=1, \mathrm{Re}=10, \mathrm{Ha}=20,{ }^{\phi}=1 \%$ and $\mathrm{Ec}=10^{-4}$

\begin{tabular}{|c|c|c|c|c|c|}
\hline $\begin{array}{c}\text { Nodes } \\
\text { (elements) }\end{array}$ & $\begin{array}{c}9613 \\
(18412)\end{array}$ & $\begin{array}{c}23534 \\
(45366)\end{array}$ & $\begin{array}{c}35665 \\
(68918)\end{array}$ & $\begin{array}{c}41178 \\
(79640)\end{array}$ & $\begin{array}{c}46902 \\
(90758)\end{array}$ \\
\hline$N u_{a v}$ & 3.538 & 3.908 & 4.115 & 4.141 & 4.152 \\
\hline
\end{tabular}

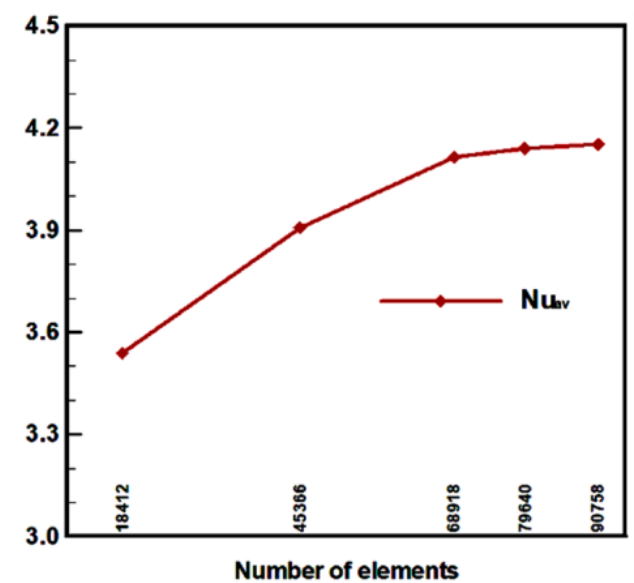

Figure 2. Grid sensitivity test.

\section{COMPUTATIONAL PROCEDURE}

The numerical procedure of the present physical problem has been performed by implementing the finite element method of Galerkin weighted residual technique. In this procedure, the solution domain is divided into subdomains by considering non-uniform triangular meshing where the non-dimensional governing equations are discretized into finite element equations which are modified into integral equations with the help of Galerkin residual method. The obtained equations are converted into linear algebraic equations by using Newton-Raphson method 
Journal of Thermal Engineering, Research Article, Vol.7, No.1, pp. 91 - 108, January, 2021

clarified by Reddy [48] and finally Triangular Factorization Technique is used to obtain a smooth solution for the entire domain. Detailed derivation of the application of this method is given by Taylor and Hood [49] and Dechumphai. [50].

\section{VALIDATION OF NUMERICL PROCEDURE}

The present simulation has been validated by comparing the present results on the basis of identical problem of Nada and Chamkha [51], Waheed [52], Abdelkhalek [53], Khanafer [54] and Sharif [55] for the computed average Nusselt number with various values of Reynolds number and Richardson number presented in Table 3. Moreover, Figure 3 represents a comparison of the streamlines and isothermal lines from the present simulation with those of Basak et al. [56] for numerical solution of mixed convection flows within a square cavity with linearly heated side walls at $\operatorname{Pr}=0.015, \mathrm{Re}=10, \mathrm{Gr}=10^{3}$. Results have been found in excellent agreement with the mentioned previous work which shows that the numerical procedure provides accurate solution for the present problem.

Table 3. Comparison of average Nusselt number for base fluid solution with previous works at $\operatorname{Pr}=0.70$

\begin{tabular}{|c|c|c|c|c|c|c|c|c|}
\hline $\mathrm{Re}$ & $\mathrm{Ri}$ & $\mathrm{a}$ & $\mathrm{b}$ & $\mathrm{c}$ & $\mathrm{d}$ & $\mathrm{e}$ & $\mathrm{f}$ & $((a-c) / c) \times 100$ \\
\hline 1 & 100 & 1.00033 & 1.006367 & 1.00033 & - & - & - & 0 \\
\hline 100 & 0.01 & 2.04392 & 2.112957 & 2.03116 & 1.985 & 2.02 & - & 0.628 \\
\hline 400 & 0.000625 & 4.05362 & 4.069035 & 4.02462 & 3.8785 & 4.01 & 4.05 & 0.720 \\
\hline 500 & 0.0004 & 4.55663 & 4.602600 & 4.52671 & - & - & - & 0.660 \\
\hline 1000 & 0.0001 & 6.48981 & 6.426109 & 6.48423 & 6.345 & 6.42 & 6.55 & 0.086 \\
\hline
\end{tabular}

${ }^{\mathrm{a}}$ Present work; ${ }^{\mathrm{b}} \mathrm{Nada}$ and Chamkha [51]; ${ }^{\mathrm{c}}$ Waheed [52] ; ${ }^{\mathrm{d}}$ Abdelkhalek [53]; ${ }^{\mathrm{e}}$ Khanafer [54]; ${ }^{\mathrm{f}}$ Sharif [55].
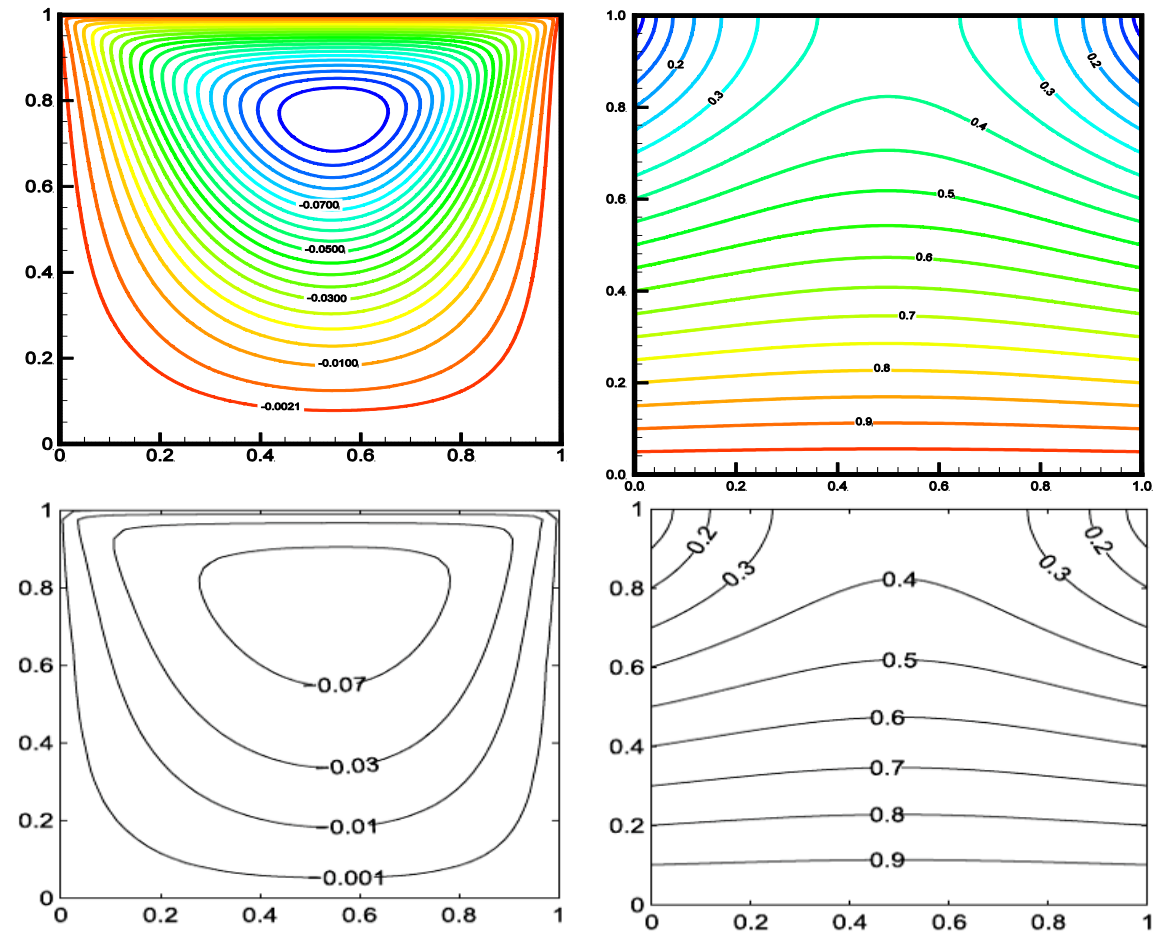

Figure 3. Comparison of streamlines (left) and isotherms (right) between present study (top) and Basak et al. [56] (bottom).

\section{RESULTS AND DISCUSSION}

The numerical results of streamlines, isotherms, average Nusselt number, average temperature and mid sectional velocities for magnetohydrodynamic mixed convection flow in a vented grooved channel filled with copper oxide-water nanofluid have been presented graphically and discussed elaborately in this section. The values of the dimensionless governing parameters such as Richardson number (Ri), Reynolds number (Re), Hartmann number (Ha) 
, concentration of nanoparticales $(\phi)$, Eckert number $(\mathrm{Ec})$ and Prandtl number (Pr) have been considered as $\mathrm{Ri}=0.1$ to $100, \mathrm{Re}=10$ to $200, \mathrm{Ha}=0$ to $100, \phi=0 \%$ to $5 \%, \mathrm{Ec}=10^{-4}$ to $10^{-1}$ and $\operatorname{Pr}=6.2$.

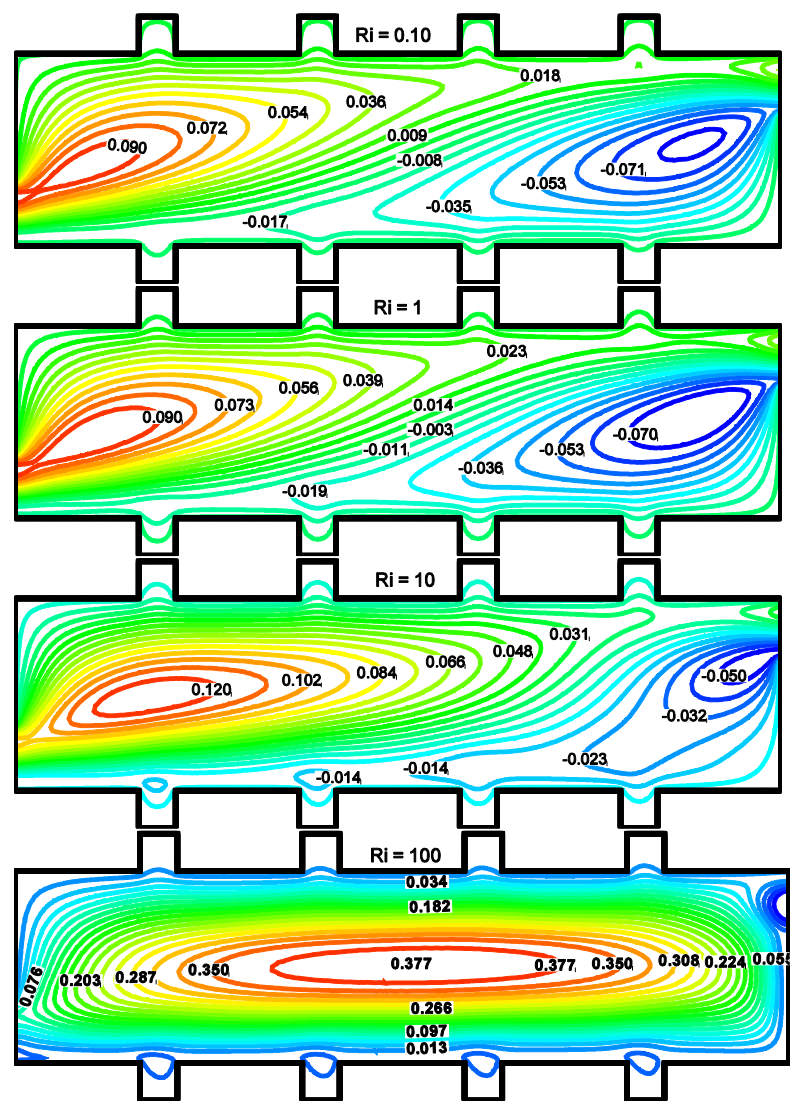

(a)

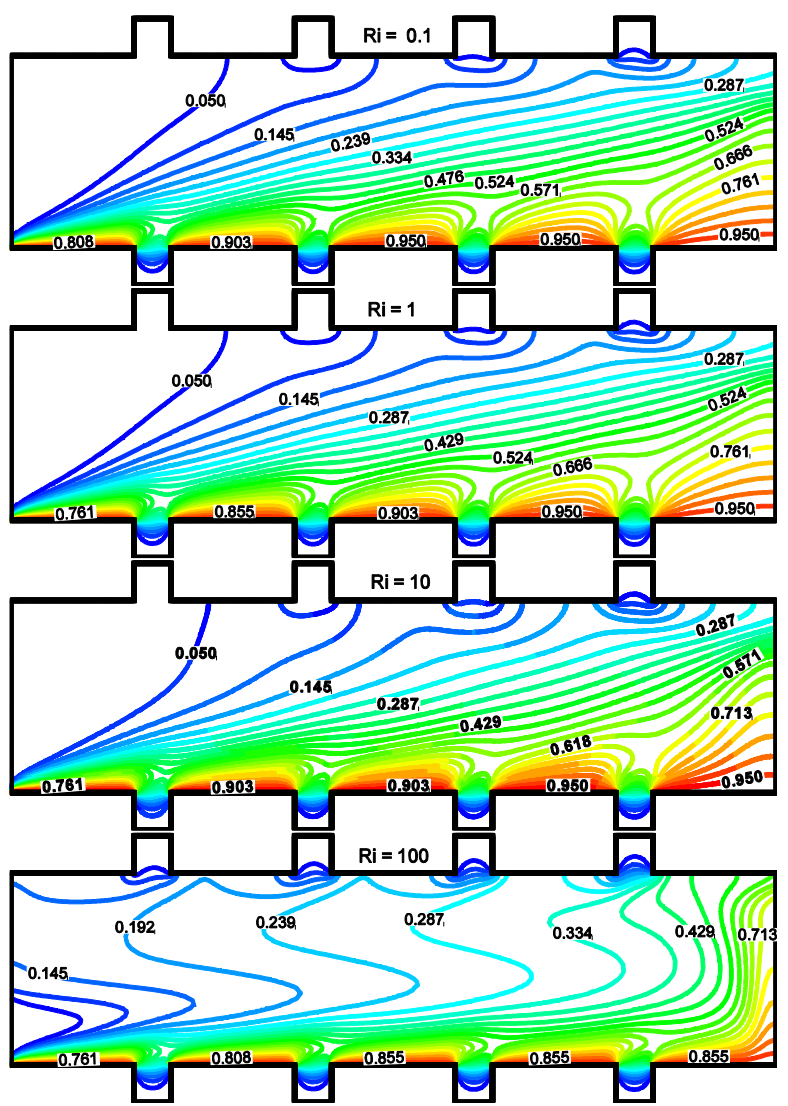

(b)

Figure 4. Effect of Ri on (a) streamlines and (b) isotherms while $\mathrm{Re}=10, \mathrm{Ha}=20, \phi=1 \%$ and $\mathrm{Ec}=10^{-4}$.

Figure 4 illustrates the streamline and isotherm plots for different values of Richardson number with certain value of controlling parameters. Richardson number characterized the dominating phenomena of convection like forced convection dominant regime for $\mathrm{Ri} \leq 0.1$, mixed convection dominant regime for $\mathrm{Ri}=1$ and free convection dominant regime for $\mathrm{Ri} \geq 1$. Thus in Figure $4(\mathrm{a})$ for $\mathrm{Ri}=0.1$, forced convection is dominant inside the channel and two recirculation zones develop adjacent to the diagonal flow path where one is near the top of the inlet port rotating in counter clock wise direction and other is near the bottom of the outlet port rotating in clockwise rotation. For $\mathrm{Ri}=$ 1 , buoyancy forces and shear forces are contributed equally on the flow field inside the channel where the vortices are qualitatively similar. The influence of buoyant force increases as Ri increases which results the flow field is dominated by free convection and the upper vortex is elongated with greater strength while the lower vortex is shrink with lower strength which leads to expedite the heat transfer rate. It is seen that both vortices vanish and forming a larger recirculation zone with higher strength for greater effect of $\mathrm{Ri}(\mathrm{Ri}=100)$ that occupies the enter region of the channel where streamlines are more concentrated near the horizontal heated walls which increases heat transfer rate there. Moreover, the streamline plots reveal that the flow strength is accelerated with increase in Ri where maxima are observed near the centre of the vortex. Furthermore, streamlines are bended close to the horizontal walls due to the presence of square grooves and single cells also appear near the entrance of lower grooves with increasing Ri which leads to enhancement of heat transfer rate there. On the other hand in Figure 4(b), it is seen that isotherms are emanated from the bottom to top as well as in the direction of exit port for lower Ri, and less influenced up to mixed convection dominant regime whereas in free convection dominant regime temperature lines are condensed near the bottom walls 
and moves in wavy shaped with higher temperature gradient toward the exit port which supports the stronger free convection effect inside the channel.

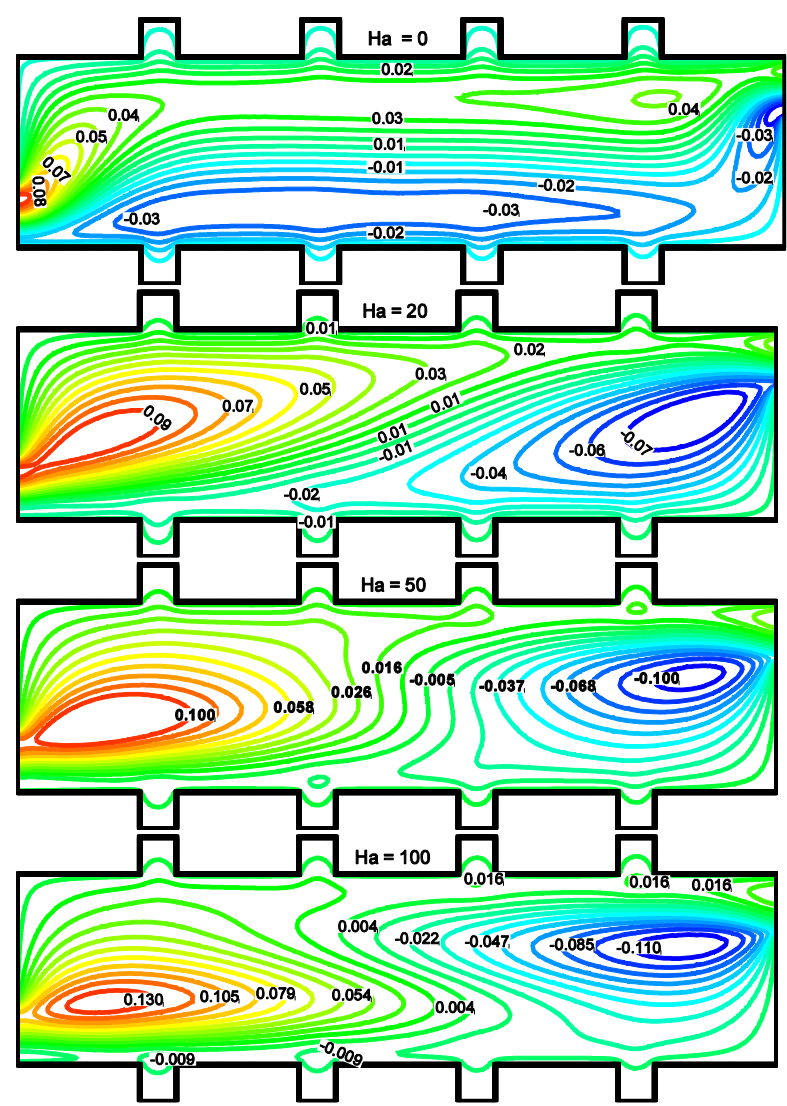

(a)

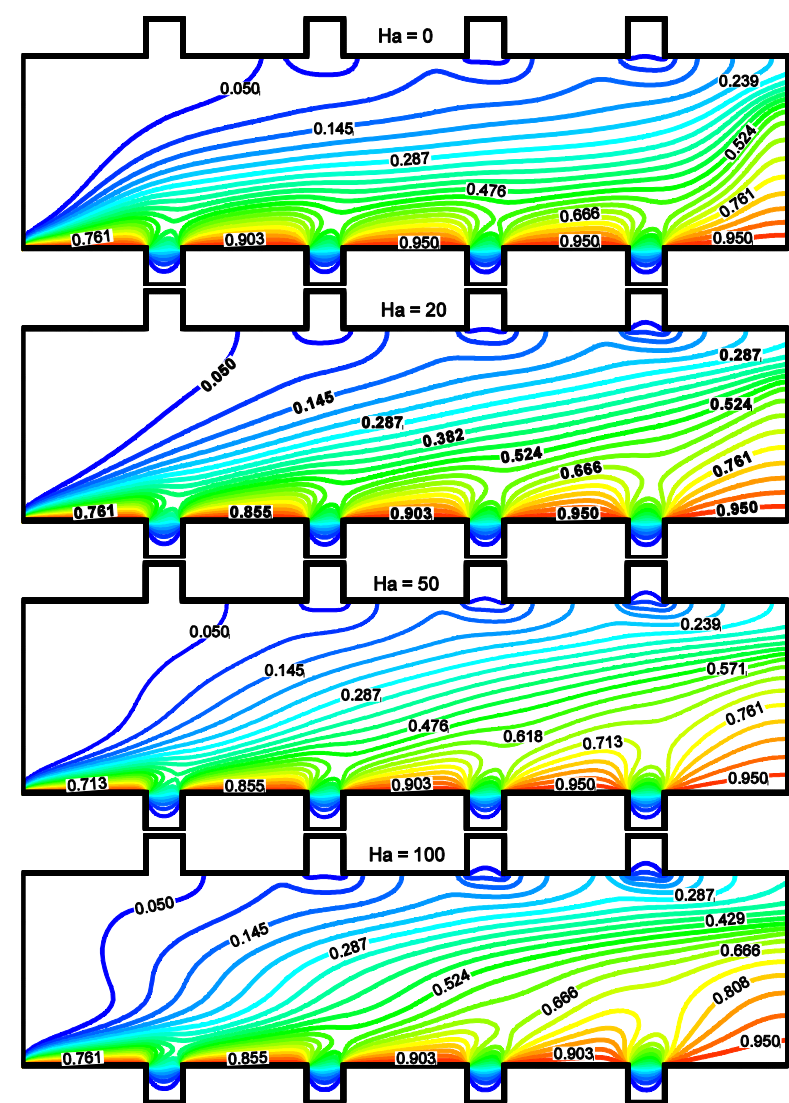

(b)

Figure 5. Effect of Ha on (a) streamlines and (b) isotherms while $\mathrm{Ri}=1, \mathrm{Re}=10, \phi=1 \%$ and $\mathrm{Ec}=10^{-4}$.

Figure 5 displays the effect of magnetic field on streamlines and isotherms while the flow field is governed by mixed convection flow. In absence of magnetic field $(\mathrm{Ha}=0)$, the streamlines are stretched out in the direction of flow that occupies the entire channel and complete cells also appear within the flow field. The shape and strength of the flow circulation within the channel is modified with increase in Ha and produced two recirculation zones beside the main flow path. It is also found that the complete cells disappear with increase in Ha which reduces the heat transfer from the source. Moreover, in Figure 5 (a), it is observed that the vortices are elongated with higher strength and the diagonal streamlines are twisted for increasing Ha from 50 to 100 which causes a reduction in flow strength as well as heat transfer. The physical fact behind it is that active Lorentz's force due to applied magnetic field reduces more shear force as compared to buoyancy force. Besides this, the isotherms densely distributed near the bottom walls as seen in Figure 5(b), which exposes greater temperature region near the bottom walls. In addition, the trend of isotherm contours changes slightly with increase in strength of magnetic field which indicates weaker convection heat transfer.
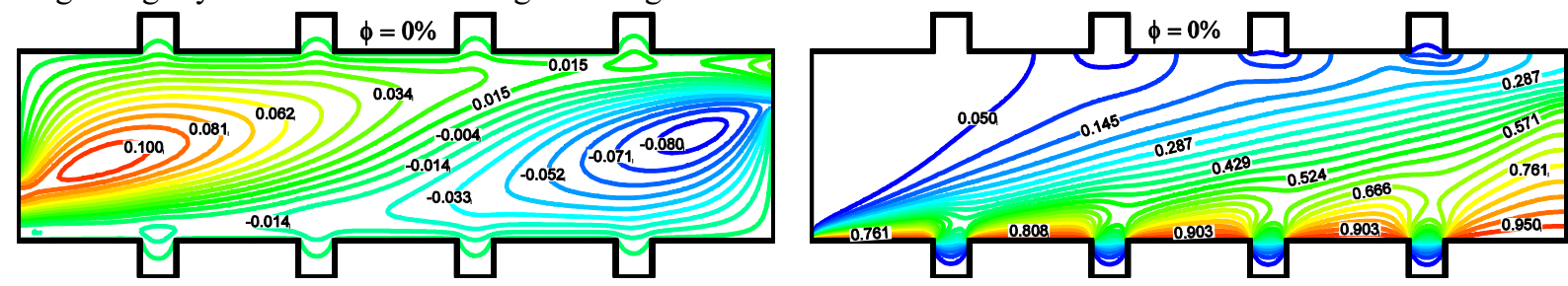


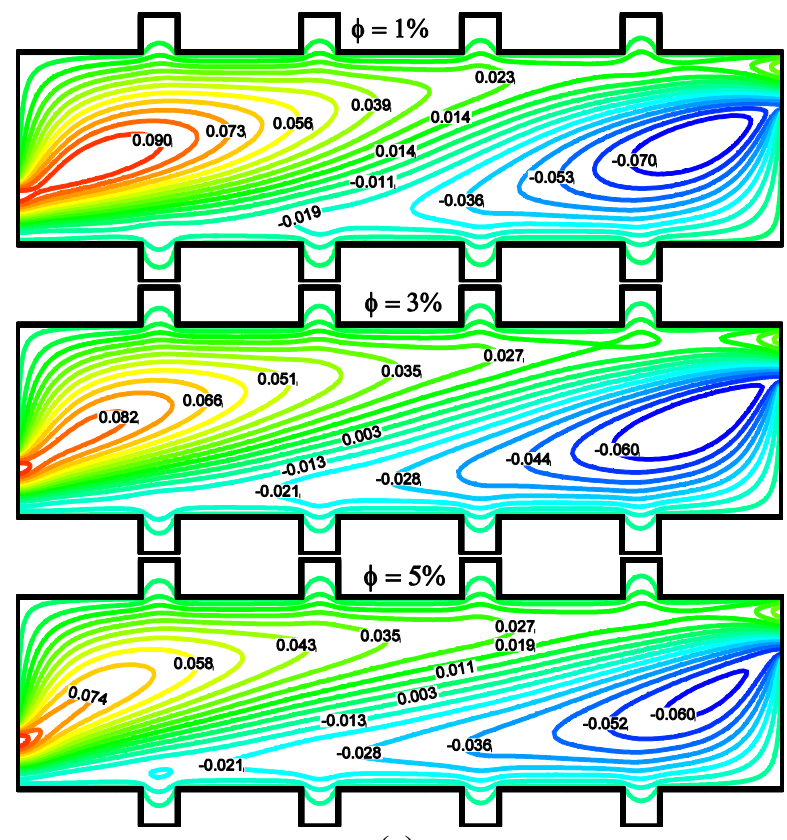

(a)

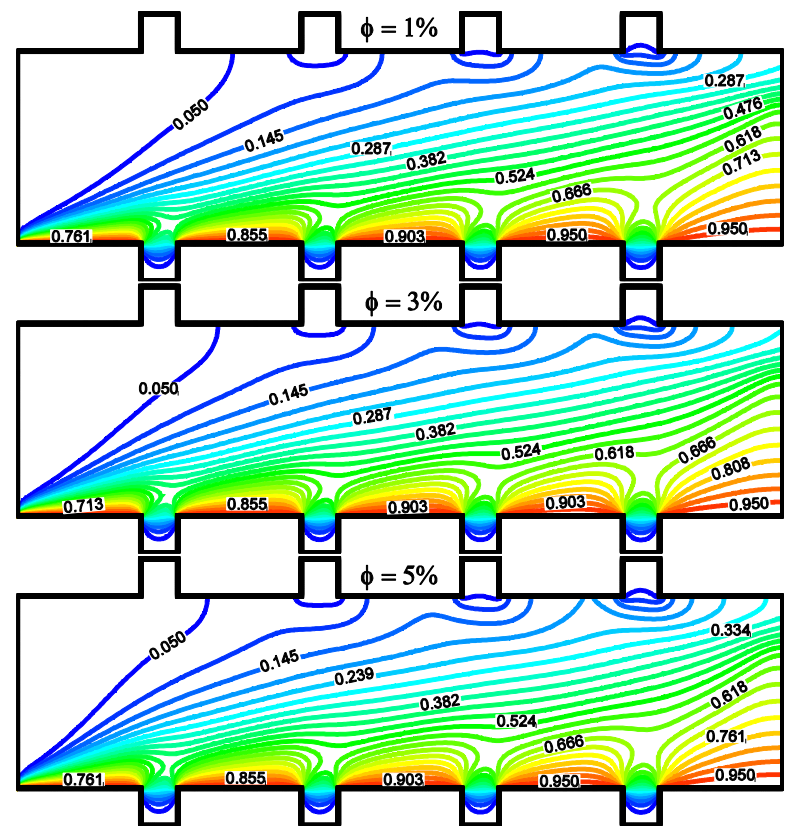

(b)

Figure 6. Effect of $\phi$ on (a) streamlines and (b) isotherms while $\mathrm{Ri}=1, \mathrm{Re}=10, \mathrm{Ha}=20$ and $\mathrm{Ec}=10^{-4}$.

Figure 6 represents the streamlines and isotherm contours for different concentration of nanoparticles at $\mathrm{Ri}$ $=1, \mathrm{Re}=10, \mathrm{Ha}=20$ and $\mathrm{Ec}=10^{-4}$. From these figures, it is clear that the flow pattern is almost similar and isotherms are less affected with the variation of concentration of nanoprticles. Thus, the flow and temperature distributions inside the channel are more sensitive due to the effects relevant parameters other than the effect of volume fraction. Moreover, the magnitude of flow circulation decreases with the increase in volume fraction. Because, dispersed nanoparticles increase the density of nanofluid. On the other hand, the temperature distribution in Figure 6(b) is dominated by conduction mode of heat transfer due to the presence of nanoparticles of higher thermal conductivity.

The computed average Nusselt number and average temperature for different values of the governing parameters have been presented in Figure 7 and Figure 8, respectively. In Figure 7(a), it is observed that the heat transfer rate characterized by average Nusselt number increases monotonically for increasing Richardson number. The increasing rate of heat transfer accelerates and decelerates respectively for increasing Hartmann number in forced convection dominant region and free convection dominant region. In addition, the heat transfer rate boosts up rapidly due to increase in volume fraction and Reynolds number and the variations are more prominent in buoyant force dominant region than forced and mixed convection region which are displayed in Figure 7(b) and Figure 7(c), respectively. These phenomena are consistent to the effects of pertinent parameters. Besides this, heat transfer profiles decline with an increase in Ec that is shown in Figure 7(d) but these profiles remain in upward direction with rising Ri.

On the other hand, the mean temperature inside the channel rises for escalating Ha and while Ri $\leq 10$ seen in Figure $8(\mathrm{a}, \mathrm{b})$ whereas opposite trend visualizes with increase in Re for all values of Ri displayed in Figure 8(c), i.e. average temperature decreases significantly with increasing of Re. Moreover, a typical mean temperature variation is observed with increasing $\mathrm{Ha}$ and $\phi$ while $\mathrm{Ri}$ varies from 10 to 102 . These are expected due to the physical consequent on governing parameters. In addition, Ec causes enhancement in average temperature that can be seen in Figure 8(d). Moreover, it is evident that the variation of average temperature is more noticeable in free convection regime as compared to forced and mixed convection regimes. 
Journal of Thermal Engineering, Research Article, Vol.7, No.1, pp. 91 - 108, January, 2021
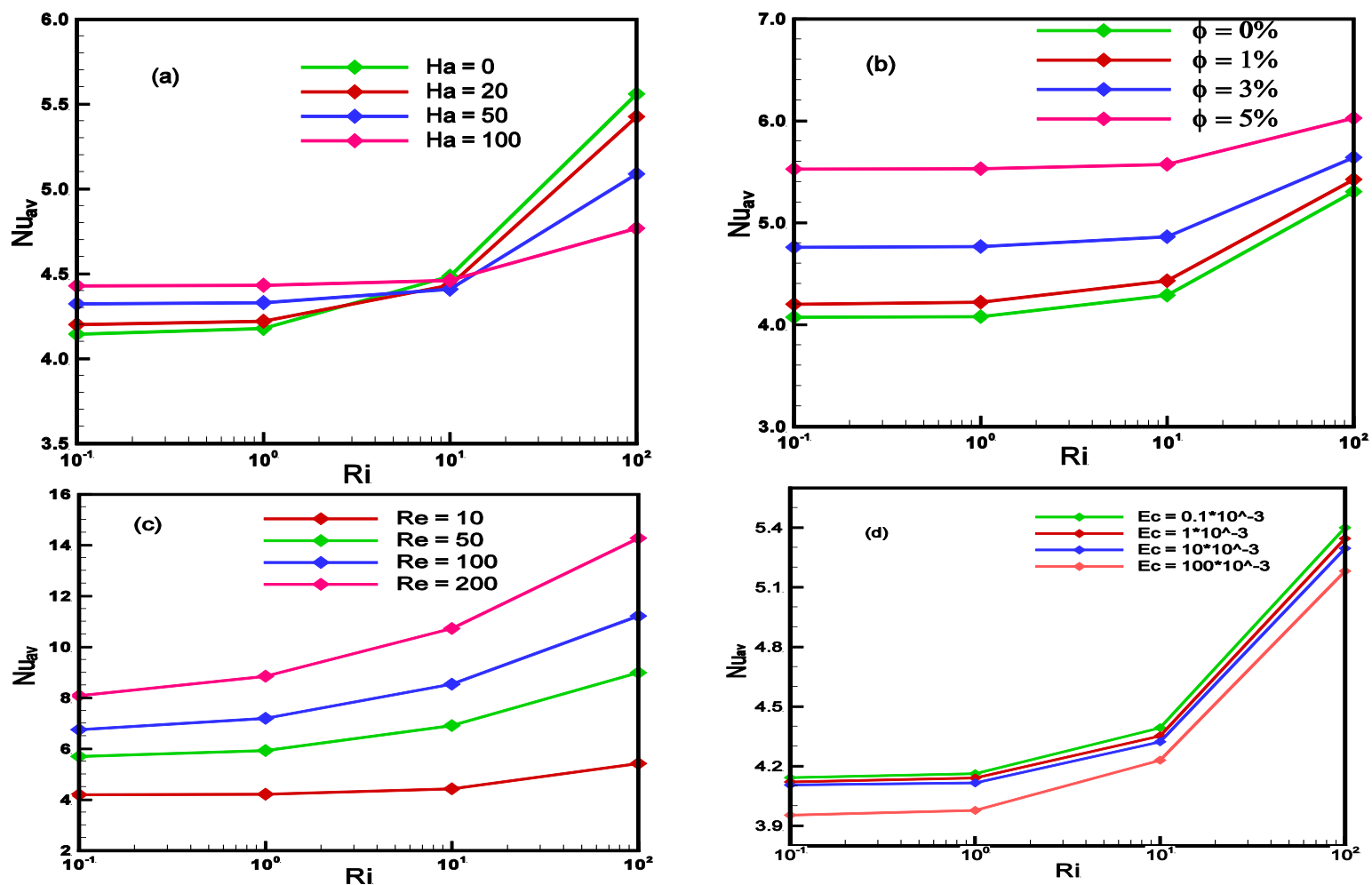

Figure 7. Average Nusselt number plots against Ri, Ha, Re, $\phi$ and Ec.
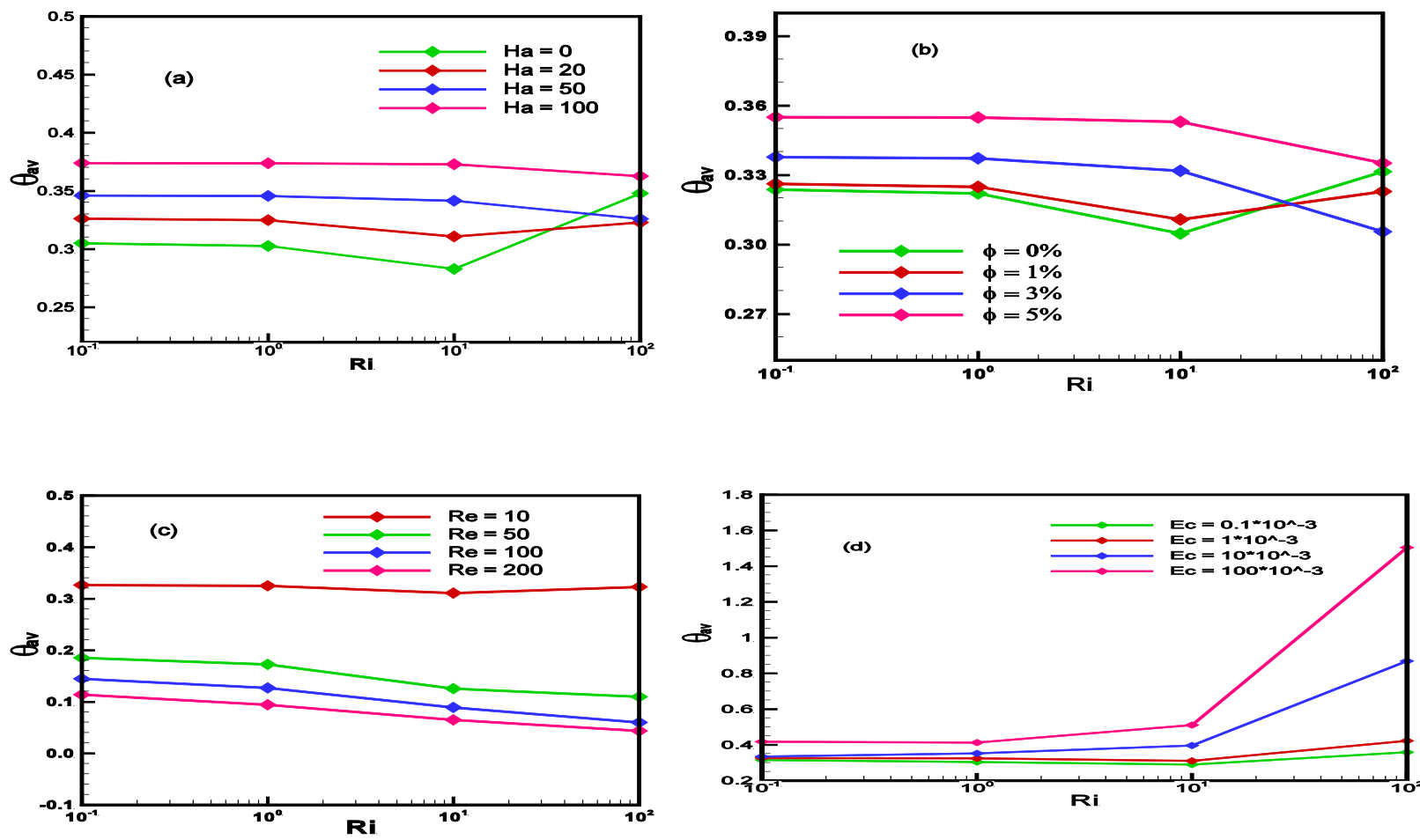

Figure 8. Average temperature plots against Ri, Ha, Re, $\phi$ and Ec. 

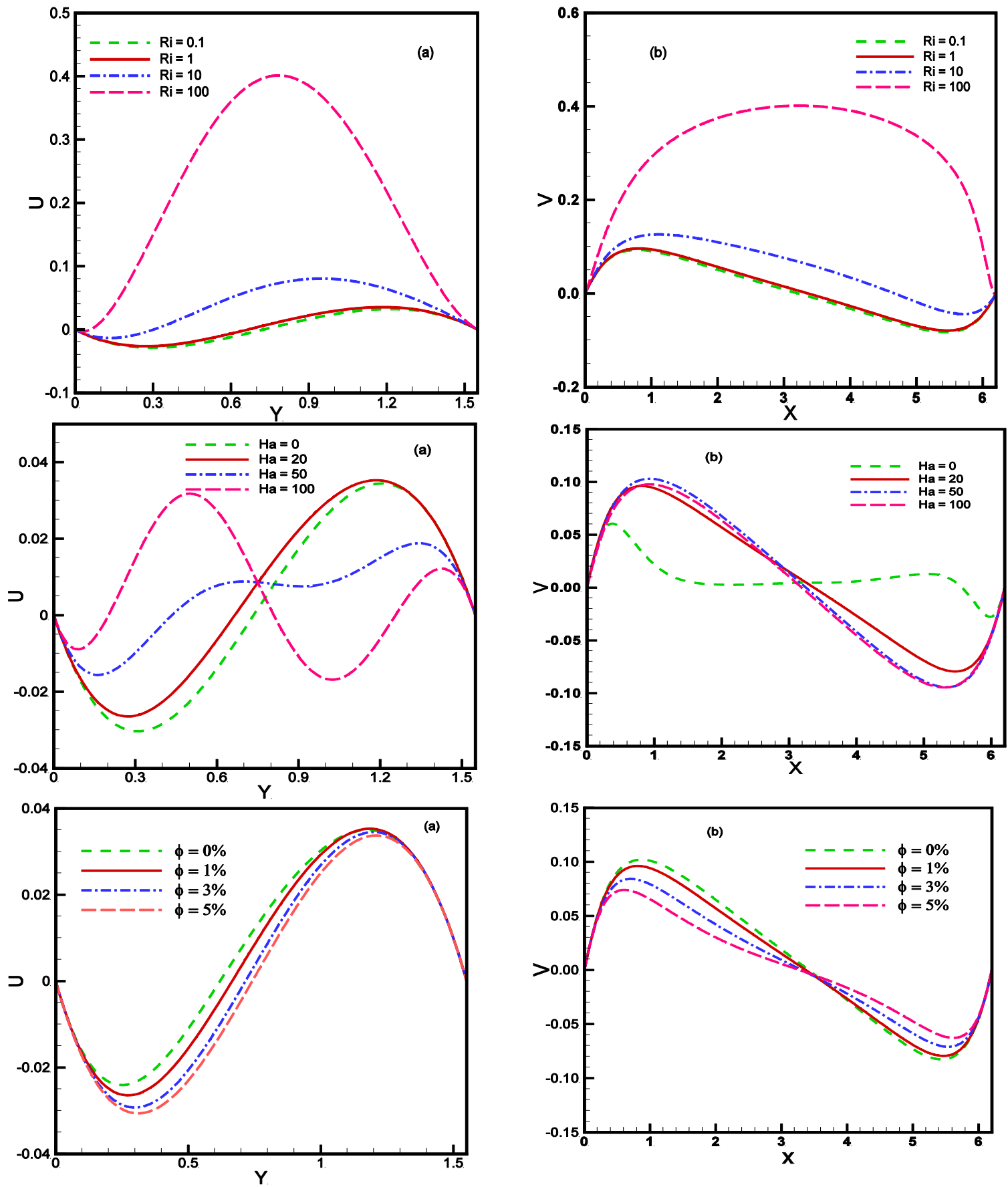

Figure 9. Mid hight $\mathrm{U}$ and $\mathrm{V}$ velocities Plot for various Ri, Ha and $\phi$.

Figure 9 demonstrates the vertical (V) and horizontal (U) velocity components along the mid section of the channel for different values of governing parameters. In Figure 9 (a), it is clear that the horizontal velocity profiles are space out remarkably for increase in pertinent parameters while the plane is located at $\mathrm{x}=0.5 \mathrm{~L}$. Moreover, the velocity profiles are less varied in forced convection regime than free convection regime. Besides this, Figure 9(b) represents the variation of vertical velocity profiles for the effects of relevant parameters while the plane is located at the $y=$ $0.5 \mathrm{H}$. The velocity components are seen to be increased with increase in Ri whereas decreased for higher concentration of nanoparticles. On the other hand, the velocity profiles are less perturbed with increase in Ha, because of increasing strength of magnetic field reduces fluid motion. 
Journal of Thermal Engineering, Research Article, Vol.7, No.1, pp. 91 - 108, January, 2021

\section{CONCLUSION}

In the present study, mixed convective flow of water based nanofluid in a vented grooved channel under the influence of magnetic field has been investigated numerically. Finite element method based on Galerkin weighted residual technique has been implemented to solve the governing equations. The numerical simulation has been carried out for a rage of physical parameters including Richardson number (Ri), from 0.1 to 100, Hartman number (Ha), from 0 to 100 and volume fraction $(\phi)$, from $0 \%$ to $5 \%$ and validity test has been performed to assess the accuracy of the present simulation and found in a good agreement. The findings of this study can be summarized as follows:

- The fluid motion and heat transfer rate inside the channel accelerates with increase in Richardson number.

- The increase in magnetic field strength and concentration of nanoparticles causes a reduction in fluid motion.

- The temperature distribution within the channel affected significantly due to the greater Richardson number, Hartmann number and volume fraction.

- Heat transfer rate increased remarkably with the increase in volume fraction and Reynolds number while reverse phenomenon was noticed for increase in Eckert number.

- Heat transfer due to magnetic field strength strongly depends on Richardson number.

- Nanofluid shows greater heat transfer enhancement than base fluid for all volume fraction of nanoparticles.

With the growing demand for efficient cooling systems, many countries are trying to develop new technologies in order to increase the heat transfer mechanisms in a more proficient way. In this regard, the present study is performed to enlighten the scientific world to improve the efficiency of heat transfer systems via an enhancement in the thermal conductivity of the traditional heat transfer fluid and also geometrical modification and it is hoped that the findings of this study would be a useful source to the researchers for the betterment of existing thermal equipments. As the present study has been numerically accomplished, experimental work is required for perfection of the numerical findings.

\section{REFERENCES}

[1] Najam, M., Amahmid, A., Hasnaoui, M., \& El Alami, M. Unsteady mixed convection in a horizontal channel with rectangular blocks periodically distributed on its lower wall. International Journal of Heat and Fluid Flow 2003;24(5):726-735. doi.org/10.1016/S0142-727X(03)00063-8.

[2] Aminossadati, S. M., \& Ghasemi, B. A numerical study of mixed convection in a horizontal channel with a discrete heat source in an open cavity. European Journal of Mechanics-B/Fluids 2009;28(4):590-598. doi.org/10.1016/j.euromechflu.2009.01.001.

[3] Ghasemi, B., \& Aminossadati, SM. Mixed convection in a lid-driven triangular enclosure filled with nanofluids. International Communications in Heat and Mass Transfer 2010;37(8):1142-1148. doi.org/10.1016/j.icheatmasstransfer.2010.06.020.

[4] Shahi, M., Mahmoudi, AH., \& Talebi, F. Numerical study of mixed convective cooling in a square cavity ventilated and partially heated from the below utilizing nanofluid. International Communications in Heat and Mass Transfer 2010;37(2):201-213. doi.org/10.1016/ j.icheatmasstransfer.2009.10.002.

[5] Fereidoon, A., Saedodin, S., Hemmat Esfe, M., \& Noroozi, MJ. Evaluation of mixed convection in inclined square lid-driven cavity filled with A12O3/water nano-fluid. Engineering Applications of Computational Fluid Mechanics 2013;7(1): 55-65. doi.org/10.1080/19942060.2013.11015453.

[6] Hussein, AK., \& Hussain, SH. Characteristics of magnetohydrodynamic mixed convection in a parallel motion two-sided lid-driven differentially heated parallelogrammic cavity with various skew angles. Journal of Thermal Engineering 2015;1(3):221-235. doi.10.18186/jte.66113.

[7] Tokgöz, N., Alıç, E., Kaşka, Ö., \& Aksot, MM. The numerical study of heat transfer enhancement using $\mathrm{Al}_{2} \mathrm{O}_{3}$ water nanofluid in corrugated duct application. Journal of Thermal Engineering 2018;4(3):1984-1997. doi.10.18186/journal-of-thermal-engineering. 409655 .

[8] Öğ̈̈t, EB. Second law analysis of mixed convection of magnetohydrodynamic flow in an inclined square liddriven enclosure. Journal of Thermal Engineering 2019;5(6):240-251. doi.10.18186/thermal.655023.

[9] Zahmatkesh, I., Ardekani, RA. Effect of magnetic field orientation on nanofluid free convection in a porous cavity: a heat visualization study. Journal of Thermal Engineering 2020;6(1):170-186. doi.10.18186/thermal.672297.

[10] Taghikhani, MA. Magnetic field effect on the heat transfer in a nanofluid filled lid driven cavity with Joule heating, Journal of Thermal Engineering 2020;6(4):521-543. doi.10.18186/thermal.764225. 
Journal of Thermal Engineering, Research Article, Vol.7, No.1, pp. 91 - 108, January, 2021

[11] Nasrin, R., Alim, MA., \& Chamkha, AJ. Combined convection flow in triangular wavy chamber filled with water- $\mathrm{CuO}$ nanofluid: effect of viscosity models. International Communications in Heat and Mass Transfer 2012;39(8):1226-1236. doi.org/10.1016/ j.icheatmasstransfer. 2012.06.005.

[12] Farsani, RY., Ghasemi, B., \& Aminossadati, SM. Magnetohydrodynamic mixed convection effects on the removal process of fluid particles from an open cavity in a horizontal channel. Journal of Heat and Mass Transfer Research 2014;1(2):67-74. doi.10.22075/JHMTR.2014.181.

[13] Abu-Mulaweh, HI. A review of research on laminar mixed convection flow over backward-and forward-facing steps. International Journal of Thermal Sciences 2003;42(9):897-909. doi.org/10.1016/S1290-0729(03)00062-0.

[14] Manca, O., Nardini, S., Khanafer, K., \& Vafai, K. Effect of heated wall position on mixed convection in a channel with an open cavity. Numerical Heat Transfer: Part A: Applications 2003;43(3) : 259-282. doi.org/10.1080/10407780307310.

[15] Manca, O., Nardini, S., \& Vafai, K. Experimental investigation of mixed convection in a channel with an open cavity. Experimental heat transfer 2006;19(1): 3-68. doi.org/10.1080/08916150500318380.

[16] Rahman, MM., Parvin, S., Saidur, R., \& Rahim, NA. Magnetohydrodynamic mixed convection in a horizontal channel with an open cavity. International Communications in Heat and Mass Transfer 2011; 8(2): 184-193. doi.org/10.1016/j.icheatmasstransfer.2010.12.005.

[17] Rahman, MM., Öztop, HF., Rahim, NA., Saidur, R., Al-Salem, K., Amin, N., \& Ahsan, A. Computational analysis of mixed convection in a channel with a cavity heated from different sides. International communications in Heat and Mass Transfer 2012; 9(1): 8-84. doi.org/10.1016/j.icheatmasstransfer. 2011.09.006.

[18] Hossain, M Z., \& Floryan, JM. Mixed convection in a periodically heated channel. Journal of Fluid Mechanics 2015;768:51-90. doi.org/10.1017/jfm.2015.48.

[19] Rafi, AA., Tonmoy, MTA., \& Hasan, MN. Numerical study of mixed convection heat transfer in an inclined rectangular channel with extruding discrete multiple heaters. In AIP Conference Proceedings $2016 ; 1754(1): 050039$. doi.org/10.1063/1.4958430.

[20] Rashidi, MM., Nasiri, M., Khezerloo, M., \& Laraqi, N. Numerical investigation of magnetic field effect on mixed convection heat transfer of nanofluid in a channel with sinusoidal walls. Journal of Magnetism and Magnetic Materials 2016;401:159-168.doi.org/10.1016/j.jmmm.2015.10.034.

[21] Carozza, A. Numerical Study on Mixed Convection in Ventilated Cavities with Different Aspect Ratios. Fluids 2018; 3(1):11. doi.org/10.3390/fluids3010011.

[22] Devera, J., \& Hyhlík, T. The effect of mixed convection on the thermal field of horizontal channel flow. In EPJ Web of Conferences 2018;180: 2019. doi.org/10.1051/epjconf/201818002019.

[23] Hussein, AK., Ahmed, SE., Mohammed, HA., \& Khan, WA. Mixed convection of water-based nanofluids in a rectangular inclined lid-driven cavity partially heated from its left side wall. Journal of computational and Theoretical Nanoscience 2013;10(9):222-2233. doi.org/10.1166/jctn.2013.3191.

[24] Mohammed, HA., Al-Aswadi, AA., Abu-Mulaweh, HI., Hussein, AK., \& Kanna, PR. Mixed convection over a backward-facing step in a vertical duct using nanofluids-buoyancy opposing case. Journal of Computational and Theoretical Nanoscience 2014;11(3):860-872. doi.org/10.1166/jctn.2014.3339.

[25] Ahmed, SE., Mansour, MA., Hussein, AK., \& Sivasankaran, S. Mixed convection from a discrete heat source in enclosures with two adjacent moving walls and filled with micropolar nanofluids. Engineering Science and Technology, an International Journal 2016;19(1):364-376. doi.org/10.1016/j.jestch.2015.08.005.

[26] Al-Rashed, AA., Kalidasan, K., Kolsi, L., Velkennedy, R., Aydi, A., Hussein, AK., \& Malekshah, EH. Mixed convection and entropy generation in a nanofluid filled cubical open cavity with a central isothermal block. InternationalJournal of Mechanical Sciences 2018;135:362-375. doi.org/10.1016/j.ijmecsci.2017.11.033.

[27] Chau, KW., \& Jiang, YW. Three-dimensional pollutant transport model for the Pearl River Estuary. Water Research 2002;36(8):2029-2039. doi.org/10.1016/S0043-1354(01)00400-6.

[28] Chau, KW., \& Jiang, YW. A three-dimensional pollutant transport model in orthogonal curvilinear and sigma coordinate system for Pearl river estuary. International Journal of Environment and Pollution 2004. doi.org/10.1504/IJEP.2004.004185.

[29] $\mathrm{Wu}, \mathrm{CL} .$, \& Chau, KW. Mathematical model of water quality rehabilitation with rainwater utilization: a case study at Haigang. International Journal of Environment and Pollution 2006. doi.org/10.1504/IJEP.2006.011227.

[30] Faizollahzadeh Ardabili, S., Najafi, B., Shamshirband, S., Minaei Bidgoli, B., Deo, RC., \& Chau, KW. Computational intelligence approach for modeling hydrogen production: A review. Engineering Applications of Computational Fluid Mechanics 2018;12(1): 38-458. doi.org/10.1080/19942060.2018.1452296.

[31] Akbarian, E., Najafi, B., Jafari, M., Faizollahzadeh Ardabili, S., Shamshirband, S., \& Chau, KW. Experimental and computational fluid dynamics-based numerical simulation of using natural gas in a dual-fueled diesel 
Journal of Thermal Engineering, Research Article, Vol.7, No.1, pp. 91 - 108, January, 2021

engine. Engineering Applications of Computational Fluid Mechanics 2018;12(1), 517-534. doi.org/10.1080/19942060.2018.1472670.

[32] Ma, Y., Luo, H., Zhang, Z., Zhou, S., \& Deng, H. Numerical modeling of dynamic characterics for combined valves in multiphase pump. Engineering Applications of Computational Fluid Mechanics 2017;11(1): 328-339. doi.org/10.1080/19942060.2017.1292409.

[33] Das, S., Jana, RN., \& Makinde, OD. Mixed convective magnetohydrodynamic flow in a vertical channel filled with nanofluids. Engineering Science and Technology, an International Journal 2015;18(2): 44-255. doi.org/10.1016/j.jestch.2014.12.009.

[34] Bansal, S., \& Chatterjee, D. Magneto-convective transport of nanofluid in a vertical lid-driven cavity including a heat-conducting rotating circular cylinder. Numerical Heat Transfer, Part A: Applications 2015;68(4):411-431. doi.org/10.1080/10407782.2014.986361.

[35] Gul, A., Khan, I., Shafie, S., Khalid, A., \& Khan, A. Heat transfer in MHD mixed convection flow of a ferrofluid along a vertical channel. PloS one 2015;10(11): e0141213.doi.org/10.1371/journal.pone.0141213.

[36] Hussain, S., Ahmed, SE., \& Akbar, T. Entropy generation analysis in MHD mixed convection of hybrid nanofluid in an open cavity with a horizontal channel containing an adiabatic obstacle. International Journal of Heat and Mass Transfer 2017;114: 1054-1066. doi.org/10.1016/j.ijheatmasstransfer.2017.06.135.

[37] McGarry, M., Campo, A., \& Hitt, DL. Numerical simulations of heat and fluid flow in grooved channels with curved vanes. Numerical Heat Transfer, Part A: Applications 2004; 46(1): 41-54. doi.org/10.1080/10407780490457653.

[38] Selvaraj, P., Sarangan, J., \& Suresh, S. (2011). Experimental investigation on heat transfer and friction factor characteristics of a water and ethylene glycol mixture flow of internally grooved tubes. International Journal of Chemical Research 2011;3(1), 3-40. doi.org/10.9735/0975-3699.3.1.33-40.

[39] Heshmati, A., Parsazadeh, M., \& Fathinia, F. Unsteady laminar convection flow over periodic grooves by using SiO2-water nanofluid. Int. J. Appl. Res. Mech. Eng. 2012; 2(2):12-18. www.interscience.in/ijarme/vol2/iss3/3.

[40] Sharma, AK., Mahapatra, PS., Manna, NK., \& Ghosh, K. Mixed convection heat transfer in a grooved channel in the presence of a baffle. Numerical Heat Transfer, Part A: Applications 2015; 67(10):1097-1118. doi.org/10.1080/10407782.2014.955359.

[41] Rabbi, KM., Rakib, T., Das, S., Mojumder, S., \& Saha, S. MHD mixed convection analysis in an open channel by obstructed Poiseuille flow of non-Newtonian power law fluid. In AIP Conference Proceedings $2016 ; 1754$ (1):050030.doi.org/10.1063/1.4958421

[42] Ali, MM., Alim, MA., \& Ahmed, SS. Numerical Simulation of Hydromagnetic Natural Convection Flow in a Grooved Enclosure Filled with $\mathrm{CuO}-$ Water Nanofluid Considering Brownian Motion. International Journal of Applied and Computational Mathematics 2018;4(5) 125. doi.org/10.1007/s40819-018-0563-1.

[43] Ali, MM., Alim, MA., \& Ahmed, SS. Oriented magnetic field effect on mixed convective flow of nanofluid in a grooved channel with internal rotating cylindrical heat source. International Journal of Mechanical Sciences 2019;151:385-409. doi.org/10.1016/j.ijmecsci.2018.11.027.

[44] Abbaszadeh, M., Ababaei, A., Arani, AAA., \& Sharifabadi, AA. MHD forced convection and entropy generation of $\mathrm{CuO}$-water nanofluid in a microchannel considering slip velocity and temperature jump. Journal of the Brazilian Society of Mechanical Sciences and Engineering 2017;39(3):775-790. doi.org/10.1007/s40430-0160578-7.

[45] Pak, BC., \& Cho, YI. Hydrodynamic and heat transfer study of dispersed fluids with submicron metallic oxide particles. Experimental Heat Transfer an International Journal $1998 ; 11(2): 151-170$. doi.org/10.1080/08916159808946559.

[46] Garnett, JM. Colours in Metal Glasses and in Metallic Films. Proceedings of the Royal Society of London 1904. doi/10.1098/rsta.1904.0024.

[47] Cui, W., Shen, Z., Yang, J., \& Wu, S. Modified prediction model for thermal conductivity of spherical nanoparticle suspensions (nanofluids) by introducing static and dynamic mechanisms. Industrial \& Engineering Chemistry Research 2014;53(46):18071-18080. doi.org/10.1021/ie503296g.

[48] Reddy, JN. An Introduction to Finite Element Analysis, McGraw-Hill, New-York 1993. ISBN 0-07-015346-5.

[49] Taylor, C., \& Hood, P. A numerical solution of the Navier-Stokes equations using the finite element technique. Computers \& Fluid 1973;1(1):73-100. doi.org/10.1016/0045-7930(73)90027-3.

[50] Dechaumphai, P. Finite Element Method in Engineering, 2nd ed. Chulalongkorn University Press, Bangkok 1999.

[51] Abu-Nada, E., \& Chamkha, AJ. Mixed convection flow in a lid-driven inclined square enclosure filled with a nanofluid. European Journal of Mechanics-B/Fluids 2010;29(6):472-482. doi.org/10.1016/j.euromechflu.2010.06.008. 
Journal of Thermal Engineering, Research Article, Vol.7, No.1, pp. 91 - 108, January, 2021

[52] Waheed, MA. Mixed convective heat transfer in rectangular enclosures driven by a continuously moving horizontal plate. International Journal of Heat and Mass Transfer 2009;52(21-22):5055-5063. doi.org/10.1016/j.ijheatmasstransfer.2009.05.011.

[53] Abdelkhalek, MM. Mixed convection in a square cavity by a perturbation technique. Computational Materials Science 2008;42(2):212-219. doi.org/10.1016/j.commatsci.2007.07.004.

[54] Khanafer, KM., Al-Amiri, AM., \& Pop, I. Numerical simulation of unsteady mixed convection in a driven cavity using an externally excited sliding lid. European Journal of Mechanics-B/Fluids 2007;26(5):669-687. doi.org/10.1016/j.euromechflu.2006.06.006.

[55] Sharif, MAR. Laminar mixed convection in shallow inclined driven cavities with hot moving lid on top and cooled from bottom. Applied thermal engineering 2007;27(5-6):1036-1042. doi.org/10.1016/j.applthermaleng.2006.07.035.

[56] Basak, T., Roy, S., Sharma, PK., \& Pop, I. Analysis of mixed convection flows within a square cavity with linearly heated side wall (s). International Journal of Heat and Mass Transfer 2009;52(9-10): 2224-2242. doi.org/10.1016/j.ijheatmasstransfer.2008.10.033. 